\title{
Spatial structure on ocean-exposed sandy beaches: faunal zonation metrics and their variability
}

\author{
Thomas A. Schlacher*, Luke Thompson \\ Faculty of Science, Health \& Education, University of the Sunshine Coast, Maroochydore, Queensland 4558, Australia
}

\begin{abstract}
Spatial ecological structure is expected to be amplified at interface regions, such as sandy beaches, which form the globe's largest ecotone between the oceans and the land. Yet, the dynamic and unstable nature of sandy shore habitats, coupled with the great mobility and behavioural plasticity of beach species, theoretically counteract the development and maintenance of stable spatial structure, such as faunal zonation across the intertidal. We examined spatial structure across the non-vegetated beach-face, using a large data set (3120 replicate samples distributed across 260 cross-shore transects) of intertidal macrobenthos distribution from eastern Australia. Most (94\%) distribution data of the benthic assemblage contained distinct spatial structure, evident as faunal zonation across the shore from the swash to the dunes. A general model recognised a tripartite biological division of the shore, but variability in the number of zones was pronounced. This variability implies that designs employing low temporal replication may fail to accurately describe the spatial structure on many ocean-exposed sandy beaches. Overall, our data support the prediction of distinct spatial structure based on the prominent interface traits of beach systems as well as the prediction of heterogeneity in spatial structure based on the mobility of beach species and instability of their habitat.
\end{abstract}

KEY WORDS: Spatial structure $\cdot$ Sandy shores $\cdot$ Zonation $\cdot$ Ecotones $\cdot$ Community dispersion

\section{INTRODUCTION}

Detection, description and mechanistic understanding of spatial patterns lie at the heart of ecology, both historical and contemporary (Elton 1927, Brown 1995). Spatial heterogeneity in the distribution of genes, organisms, populations, and communities relates to a wide range of ecological and evolutionary processes; hence, the analysis of spatial patterns is integral to population biology and epidemics, foodweb interactions, community dynamics, biodiversity studies, landscape ecology, and conservation biology (Legendre \& Fortin 1989). Perhaps most fundamentally, theories of how ecosystems and communities are organized pivot on discovering predictable spatial patterns within and among systems, and these patterns can be a product of, and influence, evolutionary processes at multiple scales (Levin 1992).
Spatial patterns are amplified at ecotones, where steep gradients in environmental conditions and geobiochemical processes promote the development of strong spatial structure at comparatively small scales (McClain et al. 2003, Ries et al. 2004). The largest interface regions between the biosphere's 2 largest domains - the oceans and continents - are marine shorelines. These coastal ecosystems, particularly rocky shores, have played a central role in understanding ecotone structures (Colman 1933, Stephenson \& Stephenson 1949). 'Zonation', the sequence of bands across the rocky shore gradient where each band is biologically distinct (e.g. structure, colour, and species composition), is a prime example of spatial structure in ecology (Grosberg 1982, Foster 1990, Peterson 1991, Harley \& Helmuth 2003). Identifying the mechanisms that determine this zonation has greatly influenced our conceptual and theoretical under- 
standing of fundamental ecological interactions, such as competition (Underwood 1984, Iveša et al. 2010) and predation (Paine 1974). This type of analysis examining patterns and drivers of spatial heterogeneity on intertidal shores continues unabated (Meager et al. 2011, Mislan et al. 2011, Valdivia et al. 2011).

Ocean-exposed sandy beaches form over $70 \%$ of ice-free coastlines, making them the geographically longest ecological interface region between marine and terrestrial biomes globally (Bascom 1980). Theoretically, sandy beach ecosystems have detectable spatial structure across the land-sea gradient. There has, however, been some debate about whether biological zonation on beaches is less distinct than on rocky shores (Brazeiro \& Defeo 1996). Several properties of beach habitats and organisms can, arguably, make spatial structure less distinct and more variable than on rocky shores: (1) beaches are dynamic, malleable, and unstable habitats; (2) sandy beach organisms are mobile, continually re-adjusting their vertical and horizontal position; and (3) behavioural plasticity is a key trait of sandy beach organisms, and such plastic behaviour can result in variable distributions (McLachlan \& Jaramillo 1995, Brown 1996, Schlacher et al. 2008b).

Expectations are that the unique features of beach systems - instability and variability of habitats combined with the plastic behaviour and mobility of organisms - result in indistinct, or at least variable, zonation structures: this is the core predictive hypothesis and justification for the present study. Specifically, we examined the zonation structure of sandy beaches in terms of 3 interrelated, thematic areas, set out in detail in Table 1: (1) 'zone metrics': the existence, number, and variability of biological zones and the species characterising such zones; (2) 'boundaries and consistency': the distinctiveness of faunal discontinuities and heterogeneity within faunal bands; and (3) 'environmental drivers': links between the spatial structure of habitat properties and species distributions.

\section{MATERIALS AND METHODS}

\section{Study sites and field collections}

The distribution of benthic invertebrates across the intertidal zone was quantified on 4 exposed sandy beaches located on the east coast of Australia (Fig. 1). The beaches are described in detail by Schlacher et al. (2008a). Briefly, they are typically of the intermediate morphodynamic type (Dean's parameter: 1.6 to
3.8), the intertidal zone spans 57 to $75 \mathrm{~m}$ from the base of the dunes to the swash and slopes relatively gently $\left(2.1\right.$ to $\left.2.6^{\circ}\right)$, the sediments are composed mostly of medium-grained sands (272 to $371 \mu \mathrm{m}$ ), and all sites are fronted by 100 to $200 \mathrm{~m}$ wide surf zones with typical waves being 0.8 to $1.8 \mathrm{~m}$ high and breaking at a period of 12 to $20 \mathrm{~s}$ (Schlacher et al. 2008a). All 4 beaches are fully exposed to the predominant SE swell (Fig. 1). The driftline (i.e. band of accumulated wrack, carrion, and flotsam) is commonly located at the base of the dunes. However, all beaches receive only very small amounts of stranded material, usually making the driftline much less distinct than on beaches with large deposits of drift algae or seagrass.

\section{Field collections}

Biological distribution patterns were recorded by sampling the benthic fauna from 12 levels spread across 5 replicate transect lines (30 $\mathrm{m}$ apart along the shore) that ran from the base of the foredunes to the swash. The distance between the 12 sampling levels was adjusted to cover the entire intertidal zone, but was usually 5 to $7 \mathrm{~m}$. At each level, 5 core samples (inner diameter: $15.4 \mathrm{~cm}$; depth: $30 \mathrm{~cm}$ ) were taken and pooled. Placement of the 5 cores was at the same elevation, and shore-parallel positions of cores were haphazard within $5 \mathrm{~m}$ of the centre of the transect line. Pooled core samples were sieved in the swash zone through mesh bags ( $1 \mathrm{~mm}$ aperture size) to separate the fauna from the sediment.

At the same levels where fauna cores were extracted, triplicate sediment cores were collected (30 mm diameter, $100 \mathrm{~mm}$ deep) and pooled per level. In the laboratory, sand moisture was measured as the weight loss after drying to constant weight $\left(65^{\circ} \mathrm{C}, 48 \mathrm{~h}\right)$. Granulometry was determined by drysieving, using a nested series of sieves with mesh sizes of 4000, 2000, 1000, 500, 250, 125, and $63 \mu \mathrm{m}$. Sediment statistics (e.g. mean grain size, sorting, skewness, kurtosis, etc.) were calculated with the GRADISTAT software, using the Folk \& Ward method (Blott \& Pye 2001).

All sites were sampled 13 times over 4 years from August 2005 to June 2009 (Fig. 1C). Per event, the 4 sites were sampled on 4 consecutive days (sequence of sites randomised per event) around spring tides, with the frequency and interval between sampling events largely determined by resource availability. The total sampling effort was 3120 replicates (i.e. 12 samples per transect, $\times 5$ transects per site, $\times 4$ sites, $\times 13$ times). 


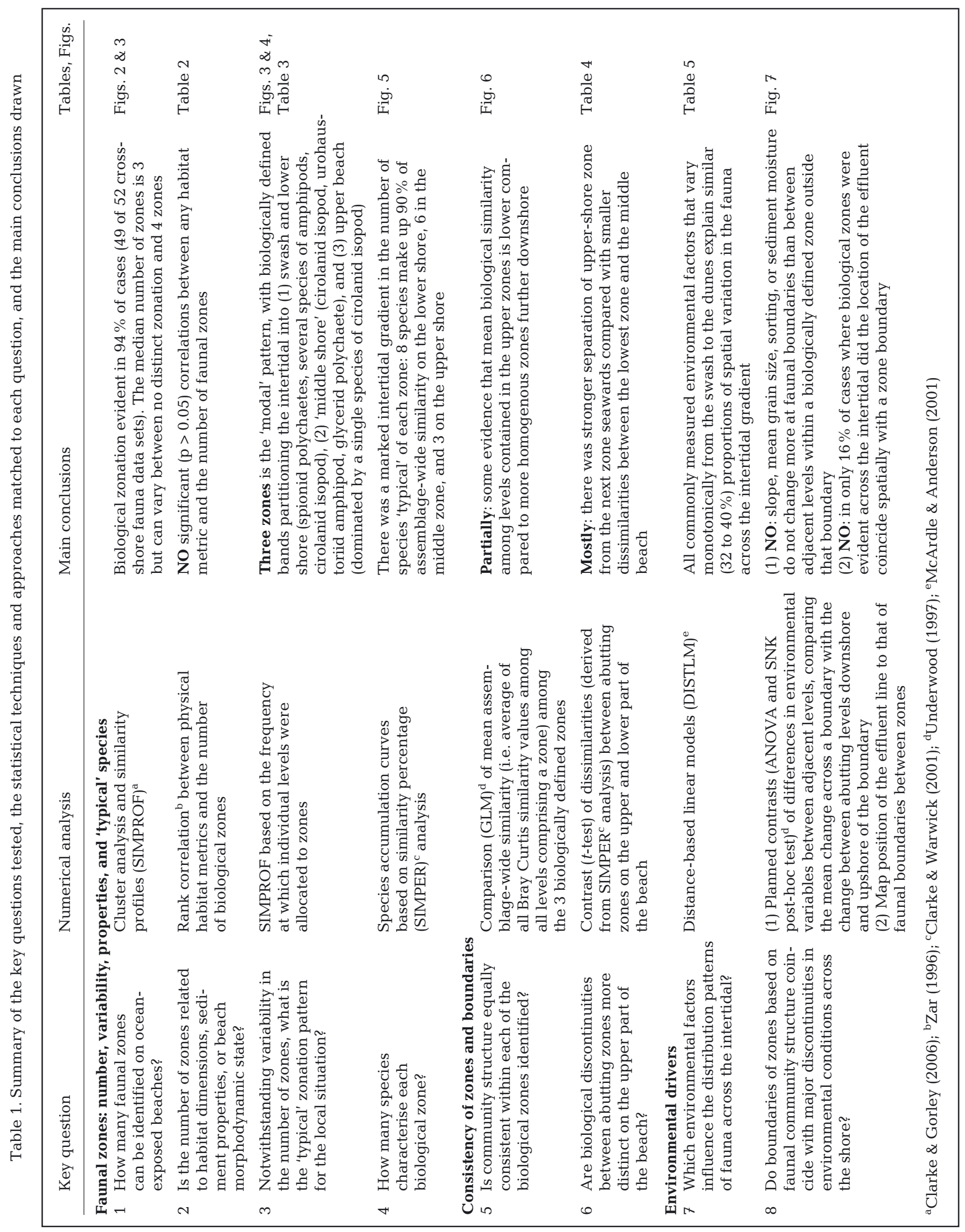




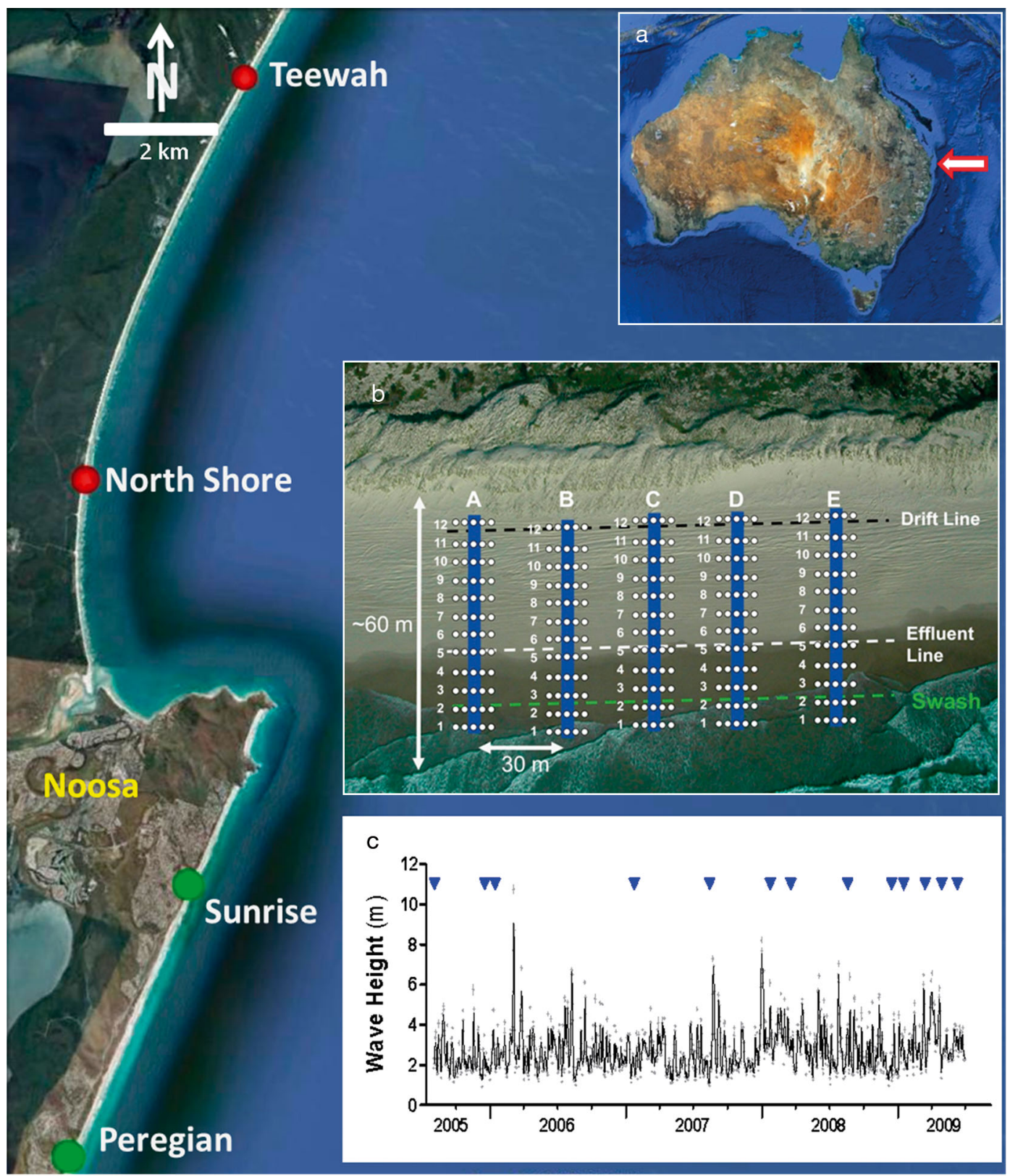

Fig. 1. Study area showing 4 beach sites sampled (red and green dots: sites with and without vehicles, respectively). (a) Location of the study site in Eastern Australia. (b) Spatial layout of the fauna collections; 5 core samples were taken from each of 12 levels arranged on 5 transects (A to E) that extended from the base of the dunes to the swash zone (photo: T. A. Schlacher). (c) Timing of 13 sampling events $(\boldsymbol{\nabla})$ in relation to variation in wave height from 2005 to 2009 (wave data courtesy of the Queensland Environmental Protection Agency)

\section{Data analyses}

We addressed a series of questions listed, together with their corresponding statistical techniques, in Table 1.

A central question was whether zonation can be objectively identified using the full set of community data available; this was tested with cluster analysis, followed by similarity profiles (SIMPROF) to determine whether clusters (i.e. zones) represent patterns in community structure that are significantly $(\mathrm{p}<$ 0.05 ) different from random spatial structure among the 12 levels sampled across the intertidal gradient (Clarke \& Gorley 2006). The cluster analysis and other multivariate methods used were based on Bray-Curtis resemblance coefficients on square-root 
transformed species abundance data. Because we found considerable variation in the number of zones between the 52 sets of cross-shore data sets (i.e. 4 sites $\times 13$ times), the 'modal' pattern of zonation was identified by first tabulating the frequency at which a level was assigned to a zone in individual SIMPROF tests run separately for each of the 52 independent sets and then subjecting this 'frequency matrix' to a further cluster/SIMPROF analysis.

It has been hypothesized that communities on the lower shore are more variable than those on the upper shore (McLachlan \& Jaramillo 1995). We tested this prediction by comparing community-wide similarity (i.e. 'internal' similarity) within biologically defined zones between the lower and upper shore. Replicate values of community-wide similarity for this test came from similarity percentage (SIMPER) analyses (Clarke \& Warwick 2001) run independently for each site $\times$ time combination. Group membership in the SIMPER analysis was defined by clusters identified in preceding SIMPROF analyses. A complementary analysis tested whether boundaries between abutting zones are more clearly defined on the upper or lower part of the beach; this test was based on contrasting dissimilarities between abutting zones, using SIMPER outputs for individual data sets.

We assessed which environmental variables influence the across-shore spatial patterns in community structure with distance-based linear models (McArdle \& Anderson 2001). Because all habitat metrics change in a similar way across the intertidal gradient, all predictors in these models are collinear. Consequently, we only used the statistics from marginal tests for individual variables. Marginal tests were run for each replicate data set of across-shore distributions independently, and the statistics (i.e. F statistics and $\mathrm{R}^{2}$ ) were averaged for each predictor variable in the models.

To test whether faunal boundaries occur at pronounced environmental 'step' changes across the intertidal, we compared the magnitude of change in key habitat descriptors (e.g. grain size and sediment moisture) between adjacent sampling levels at biologically defined boundaries and next to such boundaries. If biological boundaries are primarily defined by environmental discontinuities, the expectation is that mean environmental gradients are steeper at biological boundaries (i.e. differences in the value of environmental variables between 2 levels that fall either side of a biological boundary are expected to be larger than those between the next pair of adjacent levels not falling on a boundary).
The position of the water table outcrop on the beach face, the 'effluent line' (EL), presents a prominent and clearly defined environmental boundary on the beach face. Whether this boundary also biologically partitions the shore was tested by calculating how often the EL coincided with a faunal zone boundary.

\section{RESULTS}

\section{Faunal zones: number, variability, and typical species}

We found distinct biological zones across the intertidal gradient in $94 \%$ of cases (49 of 52 cross-shore fauna data sets). However, there was considerable variation in both the number of zones and how they were distributed across the intertidal gradient (Figs. 2 \& 3). In a few instances, there were no distinct biological zones (Fig. 2a). When zones could be recognized, the intertidal was sub-divided into 2, 3, or 4 bands (Fig. 2). The mean number of zones was 2.56 ( $\mathrm{SE}=0.10$ ) compared with a global average of 2.94 ( $\mathrm{SE}=2.56$; Fig. 3). The number of zones was not correlated with beach dimensions, sediment properties, or commonly used indices of morphodynamic beach state (e.g. Dean's parameter; Table 2).

Notwithstanding variability in the number of zones, a modal zonation pattern could be derived from analysing the frequency at which levels were assigned to different zones across all replicate data sets of across-shore distributions (Fig. 4); this analysis identified 3 zones:

(1) The 'lower shore and swash' is the most seaward biological zone on a relatively flat part of the beach (mean slope: $1.85^{\circ}$ ) that is composed of comparatively coarse (mean diameter: $414 \mu \mathrm{m}$ ) and saturated (mean moisture: 19.6\%) sands. Biologically, this zone is characterised by the spionid polychaete Sclolelepis sp. 1, 3 species of amphipods from the families Urohaustoriidae, Exoedicerotidae, and Platyischnopidae, and the cirolanid isopod Pseudolana elegans. Other commonly found taxa in this zone are clams, Donax deltoids and Paphies elongata, and the polychaete Glycera sp. 1 (Table 3).

(2) The 'middle shore' is a biologically defined zone landward of the swash and lower shore. Its gradient $\left(2.32^{\circ}\right)$ and grain size $(378 \mu \mathrm{m})$ are intermediate between the upper and lower parts of the beach, and the sands remain for the most part well-saturated $(17.4 \%)$. The polychaete Glycera sp. 1, the amphipod Urohaustorius halei, and the cirolanid isopod 

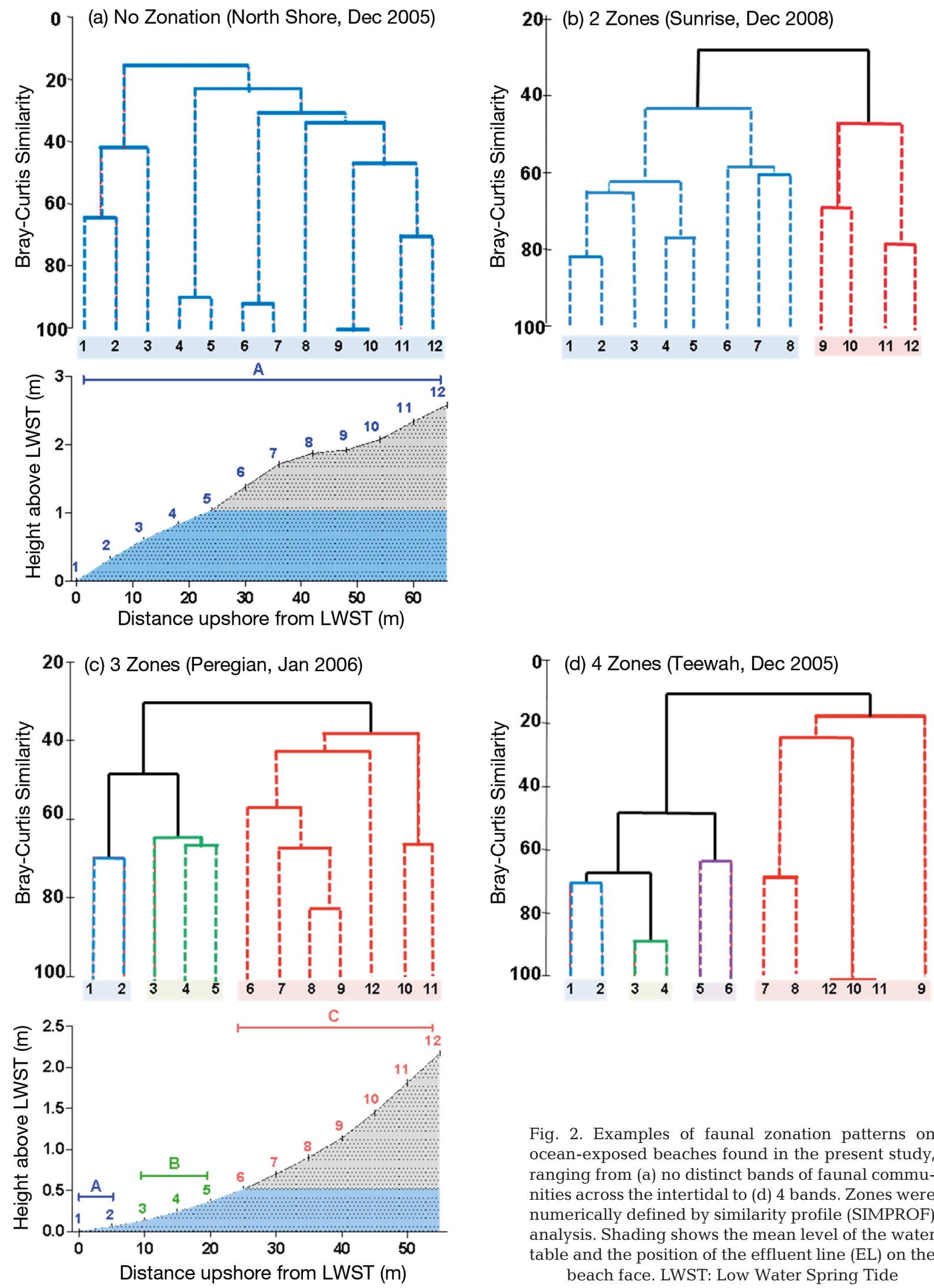

Fig. 2. Examples of faunal zonation patterns on ocean-exposed beaches found in the present study, ranging from (a) no distinct bands of faunal communities across the intertidal to (d) 4 bands. Zones were numerically defined by similarity profile (SIMPROF) analysis. Shading shows the mean level of the water table and the position of the effluent line (EL) on the beach face. LWST: Low Water Spring Tide 


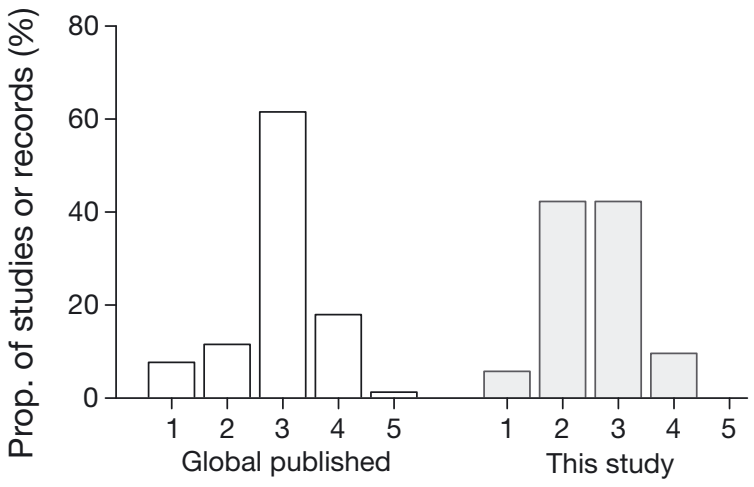

No. of biological zones (n)

Fig. 3. Frequency distribution of the number of biological zones identified in 78 sandy beach studies in (open bars) the global literature compared with (shaded bars) the present study. Data sources for literature values: Defeo et al. (1992), Haynes \& Quinn (1995), McLachlan \& Jaramillo (1995), Souza \& Gianuca (1995), Brazeiro \& Defeo (1996), Jaramillo et al. (1996), McLachlan et al. (1996, 1998), Giménez \& Yannicelli (1997), Degraer et al. (1999, 2003), Aerts et al. (2004), Gheskiere et al. (2004), Janssen \& Mulder (2005), Kotwicki et al. (2005), Fernandes \& Soares-Gomes (2006), Rodil et al. (2006), Alves \& Pezzuto (2009)

Pseudolana concinna are typical of this zone, complemented by a single species of spionid polychaete and a donacid clam (Table 3).

(3) The 'upper shore' comprises the topmost biological zone of the intertidal, where it occupies the steepest gradient of the beach face $\left(4.24^{\circ}\right)$, composed of the finest $(331 \mu \mathrm{m})$ and driest $(7.14 \%)$ sands. The fauna of this zone is dominated by a single species of cirolanid isopod Pseudolana concinna that makes up $86 \%$ of the total invertebrate abundance and contributes $72 \%$ of the community-wide similarity (Table 3).

Table 2. Correlations (Spearman rank) between sediment properties, wave characteristics, beach dimensions, and beach morphodynamic indices and the number of biological zones across the shore; all $\mathrm{r}_{\mathrm{S}} \mathrm{p}>0.05$

\begin{tabular}{|lr|}
\hline Variable & \multicolumn{1}{c|}{$\mathrm{r}_{\mathrm{S}}$} \\
\hline Grain size $(\mu \mathrm{m})$ & -0.09 \\
Coarse sand $(\%)$ & -0.17 \\
Sand moisture $(\%)$ & 0.14 \\
Max. beach elevation $(\mathrm{m})$ & 0.04 \\
Slope $\left({ }^{\circ}\right)$ & 0.01 \\
Beach width $(\mathrm{m})$ & -0.01 \\
Wave height $(\mathrm{m})$ & 0.03 \\
Wave period $(\mathrm{s})$ & 0.02 \\
Beach index $(\mathrm{BI})$ & 0.06 \\
Beach deposit index $(\mathrm{BDI})$ & 0.05 \\
Dean's parameter $(\Omega)$ & -0.01 \\
Beach state index $(\mathrm{BSI})$ & -0.01 \\
\hline
\end{tabular}

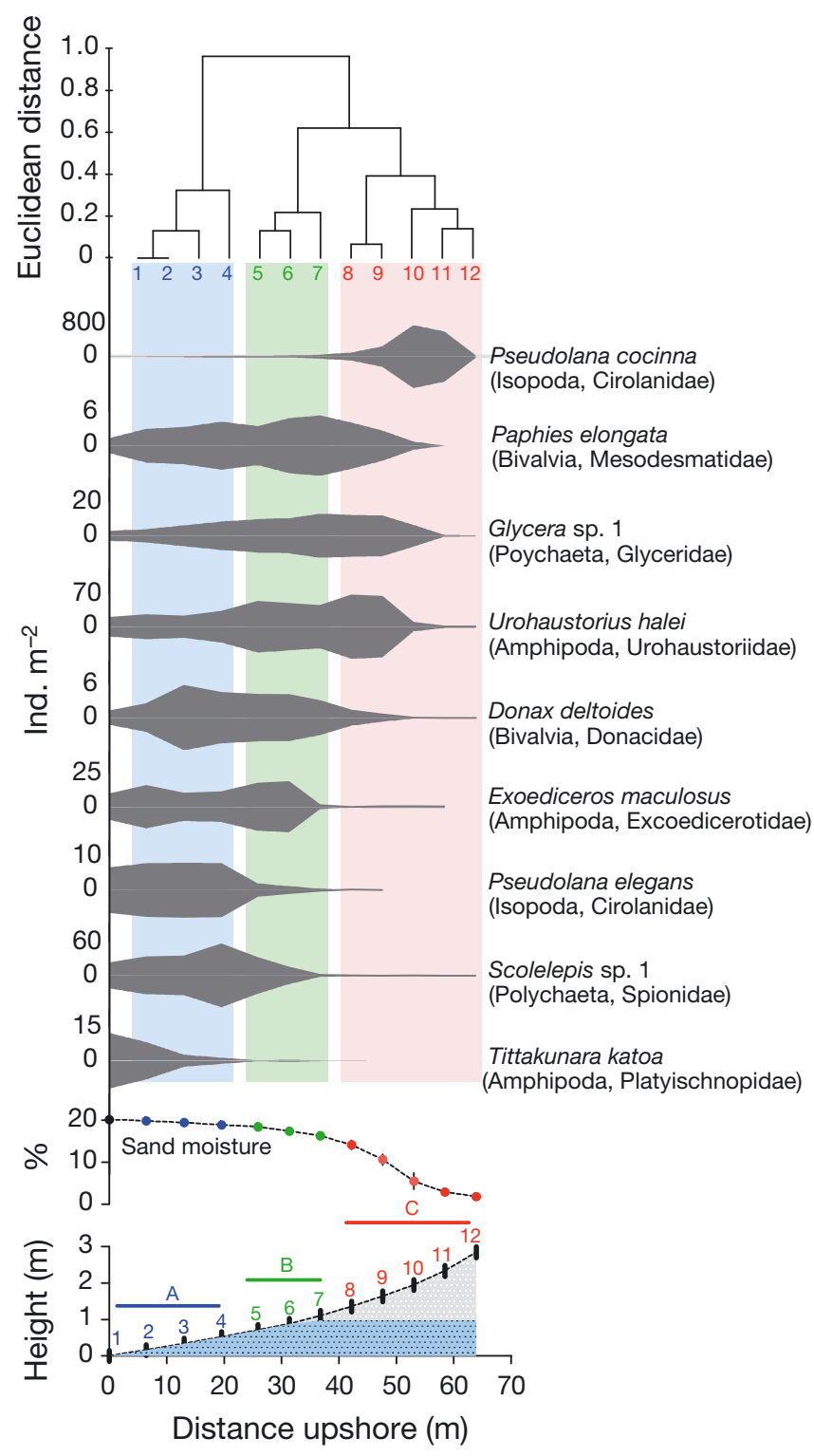

Fig. 4. Modal zonation pattern of fauna across the shore based on cluster/SIMPROF analyses of frequency distributions of levels allocated to zones across replicate data sets (top panel). Profile and gradient in sand moisture based on mean values for individual sampling levels

Overall, the number of species which characterise each zone decreases from the swash to the dunes: 4 species make up $50 \%$ of the community-wide similarity on the lower shore, 2 species in the middle zone, and a single species (Pseudolana concinna) on the upper shore (Fig. 5). Similarly, 8 species contribute collectively $90 \%$ of the similarity on the lower shores, whereas the same level of similarity is made up by only 6 species in the middle zone and by 3 species on the upper beach (Fig. 5). 
Table 3. Summary of (A) physical properties, (B) macrobenthos density and species diversity, and (C) species (parentheses: Family) 'typical' of each zone. Indicator species marked with ${ }^{*}$ in (C) are those which collectively contribute a minimum of $90 \%$ to community-wide similarity within a zone

\begin{tabular}{|c|c|c|c|c|c|c|}
\hline & \multicolumn{2}{|c|}{ Lower shore \& swash } & \multicolumn{2}{|c|}{ Middle shore } & \multicolumn{2}{|c|}{ Upper shore } \\
\hline & Mean & SE & Mean & $\mathrm{SE}$ & Mean & $\mathrm{SE}$ \\
\hline \multicolumn{7}{|l|}{ (A) Physical characteristics } \\
\hline Elevation $(\mathrm{m})$ & 0.25 & 0.03 & 0.90 & 0.06 & 2.02 & 0.06 \\
\hline Distance upshore (m) & 8.61 & 0.78 & 28.10 & 1.27 & 48.56 & 1.32 \\
\hline Slope $\left(^{\circ}\right)$ & 1.85 & 0.09 & 2.32 & 0.09 & 4.24 & 0.18 \\
\hline Sediment grain size $(\mu \mathrm{m})$ & 414.52 & 9.00 & 378.22 & 8.76 & 331.08 & 6.11 \\
\hline Moisture (\%) & 19.62 & 0.11 & 17.37 & 0.25 & 7.14 & 0.50 \\
\hline \multicolumn{7}{|l|}{ (B) Density and diversity } \\
\hline No. total individuals (ind. $\mathrm{m}^{-2}$ ) & 118.33 & 10.03 & 138.81 & 13.58 & 408.58 & 56.87 \\
\hline No. species per sample (S) & 7.26 & 0.19 & 5.91 & 0.23 & 3.24 & 0.15 \\
\hline Species diversity $(I-\lambda)$ & 0.67 & 0.02 & 0.57 & 0.02 & 0.27 & 0.02 \\
\hline \multicolumn{7}{|l|}{ (C) Indicator species } \\
\hline & $\begin{array}{l}\text { Mean density } \\
\text { (ind. } \mathrm{m}^{-2} \text { ) }\end{array}$ & $\begin{array}{c}\text { Sim. } \\
\text { contrib. }(\%)\end{array}$ & $\begin{array}{l}\text { Mean density } \\
\text { (ind. } \mathrm{m}^{-2} \text { ) }\end{array}$ & $\begin{array}{l}\text { Sim. } \\
\text { contrib. }(\%)\end{array}$ & $\begin{array}{l}\text { Mean density } \\
\quad \text { (ind. } \mathrm{m}^{-2} \text { ) }\end{array}$ & $\begin{array}{c}\text { Sim. } \\
\text { contrib. (\%) }\end{array}$ \\
\hline \multicolumn{7}{|c|}{ (12) } \\
\hline Scolelepis sp. 1 (Spionidae) & 37 & $20^{*}$ & 16 & $6^{*}$ & 1 & $<1$ \\
\hline Glycera sp. 1 (Glyceridae) & 6 & $8^{*}$ & 11 & $21^{*}$ & 7 & $11^{*}$ \\
\hline \multicolumn{7}{|l|}{ Crustacea: amphipods } \\
\hline Urohaustorius halei (Urohaustoriidae) & 25 & $10^{*}$ & 50 & $21^{*}$ & 29 & $9^{*}$ \\
\hline Exoediceros maculosus (Exoedicerotidae) & 12 & $13^{*}$ & 13 & 3 & $<1$ & $<1$ \\
\hline \multicolumn{6}{|l|}{ Crustacea: isopods } & $<1$ \\
\hline Pseudolana concinna (Cirolanidae) & 10 & $7^{*}$ & 31 & $28^{*}$ & 353 & $72^{*}$ \\
\hline Pseudolana elegans (Cirolanidae) & 8 & $12^{*}$ & 1 & 1 & $<1$ & $<1$ \\
\hline \multicolumn{7}{|l|}{ Mollusca: bivalves } \\
\hline Donax deltoides (Donacidae) & 4 & $9^{*}$ & 4 & $6^{*}$ & $<1$ & $<1$ \\
\hline Paphies elongata (Mesodesmatidae) & 3 & $5^{*}$ & 5 & $10^{*}$ & 2 & 1 \\
\hline
\end{tabular}

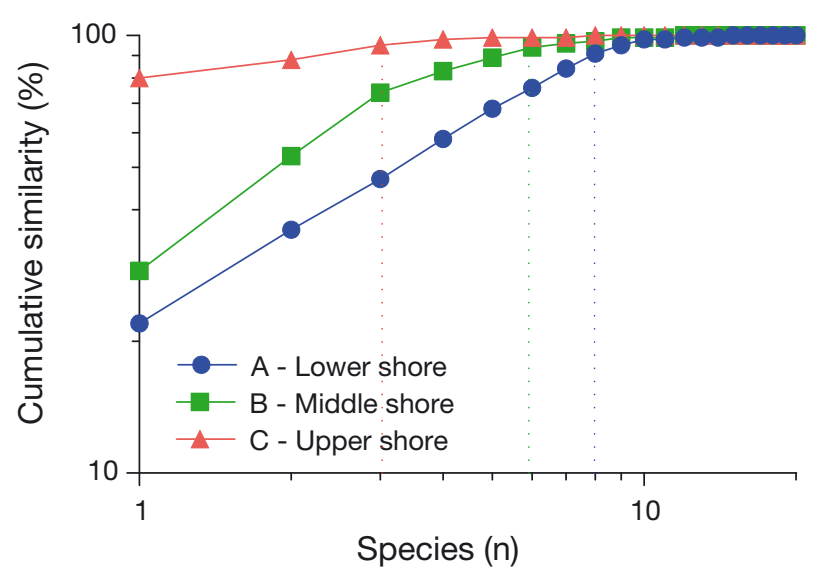

Fig. 5. Cumulative contribution of species to total, communitywide similarity within each zone. Vertical dotted lines indicate the number of species that collectively make up $90 \%$ of the similarity within a zone

\section{Consistency of zones and boundaries}

Consistency in community structure within a zone (i.e. the mean value of Bray-Curtis similarity among all levels assigned to zone) varied to some degree across the intertidal (Fig. 6). For shores where 3 dis- tinct zones could be identified, assemblages on the upper shore were significantly (ANOVA $\mathrm{p}<0.001$ ) less consistent from level to level $(\bar{x}=52.79 \pm 4.41$, mean $\pm \mathrm{SE}$ ) compared with assemblage in the middle and lower part of the shore (middle: $\bar{x}=66.18 \pm 2.76$, lower: $\bar{x}=66.86 \pm 6.13$; Fig. 6 ). In contrast, no differences in assemblage heterogeneity amongst levels were evident for data sets in which 2 or 4 zones were evident (Fig. 6). The central part of the beach was more strongly separated (in terms of differences in community structure) from the upper beach than it was from the lowest zone; this difference in biological boundary distinctiveness was more pronounced for shores with 3 biological zones (Table 4).

\section{Environmental drivers}

Not surprisingly, all environmental factors that change monotonically from the swash zone to the dunes explained a similar amount of the total variation in the faunal distribution patterns across the intertidal gradient (Table 5). Between 32\% (slope) and $40 \%$ (elevation) of spatial variation in assemblage 


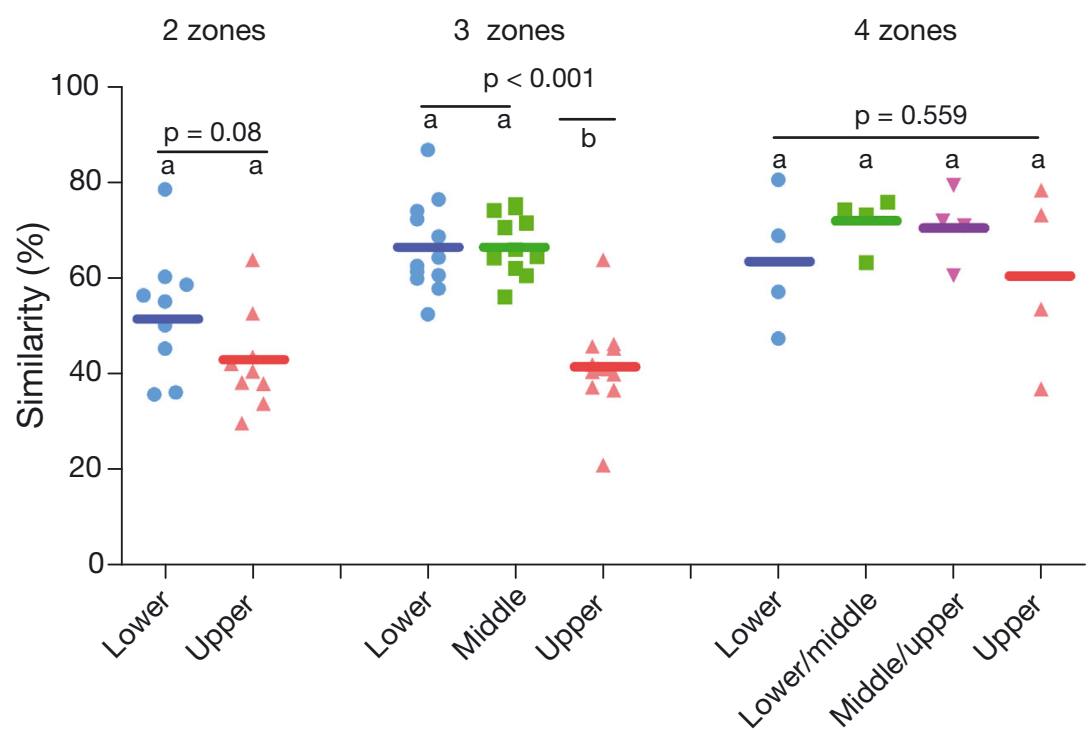

Fig. 6. Comparison of within-zone similarity (Bray-Curtis) between zones for data sets with 2, 3, and 4 biologically distinct zones across the intertidal gradient. The p-values relate to main effect in ANOVA comparing means among groups, and letters $(\mathrm{a}$ and $\mathrm{b})$ denote homogenous groups defined by SNK tests

Table 4. Bray-Curtis dissimilarities between abutting zones across the intertidal gradient for beaches where 3 and 4 distinct biological zones could be identified

\begin{tabular}{|c|c|c|c|c|c|c|}
\hline & \multicolumn{2}{|c|}{ Lower vs. middle zone } & \multicolumn{2}{|c|}{ Middle vs. upper zone } & \multirow[t]{2}{*}{$t_{(\mathrm{df})}$} & \multirow[t]{2}{*}{$\mathrm{p}$} \\
\hline & Mean & SE & Mean & $\mathrm{SE}$ & & \\
\hline Three zones & 58.62 & 2.507 & 74.79 & 1.99 & $5.06,22$ & $<0.001$ \\
\hline Four zones & 57.33 & 6.35 & 66.85 & 4.71 & $1.46,6$ & 0.200 \\
\hline
\end{tabular}

Table 5. Summary statistics for marginal tests in distance-based linear models (DISTLM) relating the distribution of intertidal invertebrates to 5 commonly measured environmental predictors

\begin{tabular}{|c|c|c|c|c|}
\hline & \multicolumn{2}{|c|}{ Pseudo- $F$} & \multicolumn{2}{|c|}{$\begin{array}{c}\text { Proportion of variance } \\
\text { explained }\end{array}$} \\
\hline & Mean & $\mathrm{SE}$ & Mean & SE \\
\hline Elevation & 6.94 & 2.10 & 0.40 & 0.07 \\
\hline Sediment moisture & 6.77 & 2.85 & 0.39 & 0.10 \\
\hline Position relative to effluent line & 5.66 & 1.89 & 0.35 & 0.08 \\
\hline Grain size (mean diameter) & 5.65 & 2.36 & 0.35 & 0.10 \\
\hline Beach-face slope & 5.15 & 2.44 & 0.32 & 0.11 \\
\hline
\end{tabular}

structure was accounted for by environmental variability (Table 5). However, boundaries between biologically defined zones (cf. Fig. 4) did not coincide with major and abrupt changes in environmental conditions (Fig. 7). For example, changes in grain size between adjacent levels were similar at the boundary of the lower to the middle zone $(\Delta 13 \mu \mathrm{m})$ to those between abutting levels immediately downshore $(\Delta 22 \mu \mathrm{m})$ and upshore $(\Delta 14 \mu \mathrm{m})$ of that boundary
(Fig. 7b). Only sediment moisture showed a larger mean gradient at the boundary between the upper and middle shore compared to levelto-level variation further downslope (Fig. 7d). However, within the uppermost zone, changes in moisture were markedly more pronounced than at the boundary (Fig. $7 d$ ). In the majority of cases $(84 \%)$, the position of the effluent line did not match a faunal boundary on the lower and middle part of the beach.

\section{DISCUSSION}

\section{Spatial structure of macrobenthos across the intertidal: metrics and variability of zonation}

Macrobenthic assemblages on ocean-exposed sandy beaches had distinct spatial structure (sensu Legendre \& Fortin 1989, Levin 1992). This spatial structure was expressed as faunal zonation across the intertidal gradient, where bands of assemblages were separated from other bands by differences in the occurrence and density of species suites (sensu Colman 1933, Stephenson \& Stephenson 1949). Yet, metrics of zonation and zonation itself appear variable on sandy shores, for both our data set and previously published accounts of zonation (Table 6).

Our general zonation classification, derived from a cluster analysis of the frequency distribution of shore levels assigned to zones, contains 3 bands (Fig. 4). A synopsis of the global literature shows that most studies also recognize a tripartite biological division of the shore (Fig. 3, Table 6): out of 78 studies in which zonation was explicitly analysed, or in which an account or description of zonation could be found, 48 (62\%) have recognized 3 biological zones. The presence of 2 or 4 zones has been less frequently identified (12 and $18 \%$, respectively), and 5 zones are described in a single study only (Table 6). 

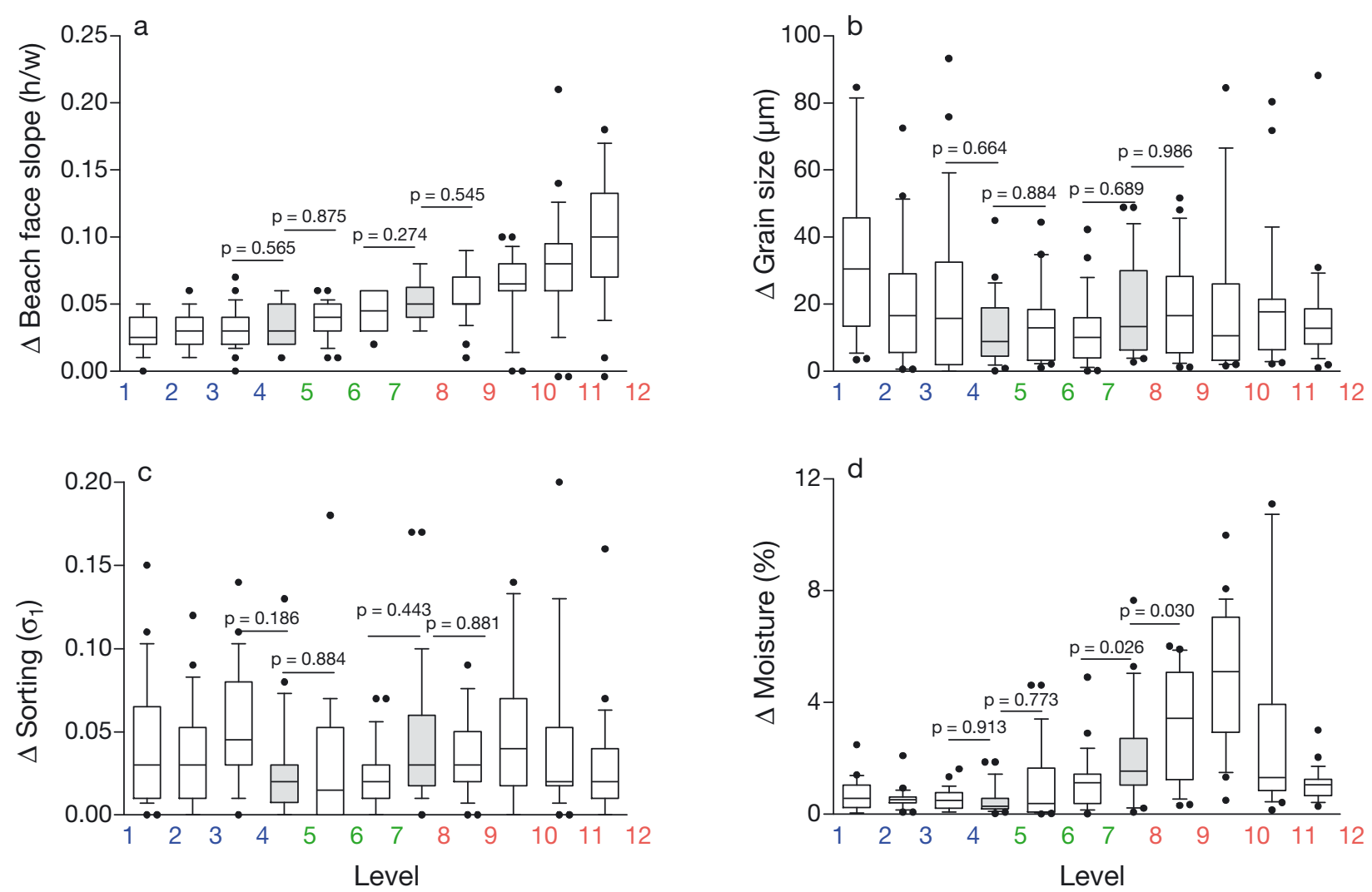

Fig. 7. Change in the values of key habitat descriptors between adjacent levels across the intertidal gradient. Shaded boxes denote zone boundaries (level 4 to level 5 and level 7 to level 8). The p-values refer to $t$-tests for differences in means between changes at zone boundaries and changes within zones abutting these boundaries. If boundaries of biological zones are primarily determined by steep gradients in environmental conditions, the expectation is that mean contrasts (shaded boxes) at boundaries are greater than (open boxes) outside of the boundaries. Boxes represent the interquartile range, whiskers the 10th and 90th percentiles, and dots are values smaller or larger than these percentiles

Some of the debates about the existence of biological zonation on sandy beaches, the consistency and distinctiveness of zones, and the number of recognized zones can be traced to inadequacies of temporal aspects in study designs. Various authors have recognized that lack of temporal replication (or low replication) can lower the accuracy and precision at which the spatial structure of macrobenthos across the intertidal is described (Haynes \& Quinn 1995). For example, working on microtidal Uruguyan beaches, Giménez \& Yannicelli (1997) demonstrate remarkably high temporal variability in the number of cross-shore zones that could be identified in successive monthly samples, ranging from no distinct faunal zonation at a site to 4 zones at the same site. Our study suggests that lack of replication may bias the number of zones described as 'typical' for a beach. Based on the full data set, we identified a general zonation scheme that recognizes a tripartite faunal division of the shore (Fig. 4). There were, how- ever, instances when fewer or more than 3 zones occurred during individual surveys; single surveys may therefore not accurately represent zonation on a shore. Yet, of 21 studies that have analysed zonation and were published after the seminal review of beach zonation by McLachlan \& Jaramillo (1995), just under half ( $\mathrm{n}=10,48 \%$ ) were based on 'spot measurements', using designs lacking in temporal replication.

It has been asserted that biological heterogeneity increases toward the swash (i.e. 'zones are clearest at the top of the shore and become increasingly blurred, moving downshore', McLachlan \& Jaramillo 1995, p. 325). We have explicitly tested this prediction and found the opposite for cross-shore data sets with a tripartite biological division of the shore: here, similarities among samples classified to form part of the upper beach were significantly lower than the observed similarties among samples further downshore (Fig. 6). 


\section{General model of zonation and characteristic species}

In their comprehensive review of sandy beach zonation, McLachlan \& Jaramillo (1995) provide a general model of beach zonation based on a thorough, qualitative synthesis of species distribution patterns from a large number of published studies. Their model contains a tripartite biological division of the shore: (1) a 'supralittoral zone' situated at and above the drift line and characterised by air-breathing crustaceans, (2) a 'littoral zone' between the drift line to around the effluent line with a more diverse mix of fauna of true intertidal species (e.g. cirolanid isopods, several families of amphipods, and spionid polychaetes), and (3) a 'sublittoral zone' extending from near the effluent line into the swash/sublittoral and characterised by the most species-rich communities composed of crabs, mysids, clams, and several families of amphipods and polychaetes.

Our data lend broad support to the McLachlan \& Jaramillo (1995) model in terms of the faunistic identity of zones. Burrowing amphipods and polychaetes are abundant on the lower ('sublittoral') and middle ('littoral') shore, complemented by bivalves and cirolanid isopods (Table 3). Cirolanid isopods were abundant across the entire beach, their distribution showing a distinct bipartite zonation between 2 species: Pseudolana elegans occurred mainly on the lower beach, whereas Pseudolana concinna dominated the assemblages of the upper shore (Fig. 4).

Ocypodid crabs are common around the drift line of the warm-temperate beaches of Eastern Australia and should therefore be considered a 'typical' species of the supralittoral zone (Barros 2001, Moss \& McPhee 2006, Lucrezi et al. 2009). However, because the crabs tunnel deeply ( $>0.5 \mathrm{~m}$ ) into the sediment, they are not routinely captured in reliable numbers by standard coring techniques that sample the macrobenthos to a depth of $\leq 0.3 \mathrm{~m}$ (Lucrezi \& Schlacher 2010, Schlacher \& Lucrezi 2010).

\section{Environmental drivers of zonation}

The range and distribution of intertidal species are in many cases set by tolerances to environmental conditions, most notably temperature, moisture, emersion time, and UV exposure (Valdivia et al. 2011). Physiological tolerances and preferences for temperature, moisture, and emersion are not uniform amongst the suite of sandy beach species (Brown 1983) and are therefore expected to shape spatial structure across the intertidal. Similarly, sediment properties (e.g. grain size) determine the burrowing performance of beach species (Nel et al. 1999, 2001, de la Huz et al. 2002) and may therefore further modify cross-shore patterns.

We found, however, no conclusive evidence that biological zones are closely matched to physical subdivisions of the habitat (e.g. above or below the water-table outcrop) or that biological zone boundaries correspond to sharp step-changes in environmental conditions across the shore (Fig. 7). Our findings are similar to previous attempts to determine the position of biological boundaries based on abiotic variables, such as moisture levels and tidal inundation (reviewed by McLachlan \& Jaramillo 1995; but see Wendt \& McLachlan 1985). However, there are no data on environmental tolerances or preferences for any sandy beach species from Australia, making interpretations about the response of individual species to environmental gradients

on sandy beaches speculative at best.
Present study $(\mathrm{n}=52)$

\begin{tabular}{cccccc} 
Present study $(\mathrm{n}=52)$ & 1 & 2 & 3 & 4 & 5 \\
\hline 3 & 22 & 22 & 5 & 0 \\
$6 \%$ & $42 \%$ & $42 \%$ & $10 \%$ & 0 \\
\hline
\end{tabular}




\section{CONCLUSIONS}

Spatial structure is generally distinct at interfaces. Exposed sandy shores form prominent interfaces and are therefore predicted to contain distinct spatial structure across the intertidal. In contrast, unstable and variable habitats that favour highly mobile species are expected to lead to less distinct or more variable spatial structure in these ecosystems. The present study lends support to both predictions: faunal distribution patterns across the intertidal gradient display distinct spatial structure in most cases, but this structure can also be variable.

Acknowledgements. We thank the jolly group of postgraduate students who extracted the stupendous number of cores, sieved tonnes (literally) of sediment by hand in the surf zone, and braved the vagaries of the Australian weather on, admittedly, stunning beaches to assemble this data set. Most tenacious were T. Nielsen, I. McLean, S. Loyd, S. Lucrezi, M. Green, and A. Holzheimer; you brave and tireless souls lifted and sieved no less than $70 \mathrm{~m}^{3}$ of beach sand by hand. L.T. was financially supported by a $\mathrm{PhD}$ scholarship from the University of the Sunshine Coast. The local government (Noosa Shire Council) financially supported part of the study.

\section{LITERATURE CITED}

Aerts K, Vanagt T, Degraer S, Guartatanga S and others (2004) Macrofaunal community structure and zonation of an Ecuadorian sandy beach (Bay of Valdivia). Belg J Zool $134: 17-24$

> Alves ES, Pezzuto PR (2009) Effect of morphodynamics on annual average zonation pattern of benthic macrofauna of exposed sandy beaches in Santa Catarina, Brazil. Braz J Oceanogr 57:189-203

Anderson MJ (2001) A new method for non-parametric multivariate analysis of variance. Austral Ecol 26:32-46

Anderson MJ (2006) Distance-based tests for homogeneity of multivariate dispersion. Biometrics 62:245-253

> Barros F (2001) Ghost crabs as a tool for rapid assessment of human impacts on exposed sandy beaches. Biol Conserv 97:399-404

Bascom W (1980) Waves and beaches: the dynamics of the ocean surface. Anchor Press, Garden City, NY

> Blott SJ, Pye K (2001) GRADISTAT: a grain size distribution and statistics package for the analysis of unconsolidated sediments. Earth Surf Process Landf 26:1237-1248

Brazeiro A, Defeo O (1996) Macroinfauna zonation in microtidal sandy beaches: Is it possible to identify patterns in such variable environments? Estuar Coast Shelf Sci 42: 523-536

Brown AC (1983) The ecophysiology of sand beach animals: a partial review. In: McLachlan A, Erasmus E (eds) Sandy beaches as ecosystems. Junk Publishers, Boston, MA

Brown AC (1996) Behavioural plasticity as a key factor in the survival and evolution of the macrofauna on exposed sandy beaches. Rev Chil Hist Nat 69:469-474

Brown JH (1995) Macroecology. University of Chicago Press, Chicago, IL
Clarke KR, Gorley RN (2006) PRIMER v6: user manual/ tutorial. PRIMER-E, Plymouth

Clarke KR, Warwick RM (2001) Change in marine communities: an approach to statistical analysis and interpretation. PRIMER-E, Plymouth

Colman J (1933) The nature of the intertidal zonation of plants and animals. J Mar Biol Assoc UK 18:435-476

Defeo O, Jaramillo E, Lyonnet A (1992) Community structure and intertidal zonation of the macroinfauna on the Atlantic coast of Uruguay. J Coast Res 8:830-839

Degraer S, Mouton I, De Neve L, Vincx M (1999) Community structure and intertidal zonation of the macrobenthos on a macrotidal, ultra-dissipative sandy beach: summer-winter comparison. Estuaries 22:742-752

> Degraer S, Volckaert A, Vincx M (2003) Macrobenthic zonation patterns along a morphodynamical continuum of macrotidal, low tide bar/rip and ultra-dissipative sandy beaches. Estuar Coast Shelf Sci 56:459-468

de la Huz R, Lastra M, Lopez J (2002) The influence of sediment grain size on burrowing, growth and metabolism of Donax trunculus L. (Bivalvia: Donacidae). J Sea Res 47: 85-95

Elton CS (1927) Animal ecology. University of Chicago Press, Chicago, IL

Fernandes RSR, Soares-Gomes A (2006) Community structure of macrobenthos in two tropical sandy beaches with different morphodynamic features, Rio de Janeiro, Brazil. Mar Ecol 27:160-169

- Foster MS (1990) Organization of macroalgal assemblages in the Northeast Pacific: the assumption of homogeneity and the illusion of generality. Hydrobiologia 192:21-33

> Gheskiere T, Hoste E, Vanaverbeke J, Vincx M, Degraer S (2004) Horizontal zonation patterns and feeding structure of marine nematode assemblages on a macrotidal, ultra-dissipative sandy beach (De Panne, Belgium). J Sea Res 52:211-226

> Giménez L, Yannicelli B (1997) Variability of zonation patterns in temperate microtidal Uruguayan beaches with different morphodynamic types. Mar Ecol Prog Ser 160: 197-207

- Grosberg RK (1982) Intertidal zonation of barnacles: the influence of planktonic zonation of larvae on vertical distribution of adults. Ecology 63:894-899

Harley CDG, Helmuth BST (2003) Local- and regional-scale effects of wave exposure, thermal stress, and absolute versus effective shore level on patterns of intertidal zonation. Limnol Oceanogr 48:1498-1508

> Haynes D, Quinn GP (1995) Temporal and spatial variability in community structure of a sandy intertidal beach, Cape Paterson, Victoria, Australia. Mar Freshw Res 46: 931-942

Iveša L, Chapman MG, Underwood AJ, Murphy RJ (2010) Differential patterns of distribution of limpets on intertidal seawalls: experimental investigation of the roles of recruitment, survival and competition. Mar Ecol Prog Ser 407:55-69

Janssen G, Mulder S (2005) Zonation of macrofauna across sandy beaches and surf zones along the Dutch coast. Oceanologia 47:265-282

Jaramillo E, Stead R, Quijon P, Contreras H, Gonzalez M (1996) Temporal variability of the sandy beach macroinfauna in South-Central Chile. Rev Chil Hist Nat 69: 641-653

Kotwicki L, De Troch M, Urban-Malinga B, Gheskiere T, Weslawski JM (2005) Horizontal and vertical distribution 
of meiofauna on sandy beaches of the North Sea (The Netherlands, Belgium, France). Helgol Mar Res 59: 255-264

Legendre P, Fortin MJ (1989) Spatial pattern and ecological analysis. Plant Ecol 80:107-138

Levin SA (1992) The problem of pattern and scale in ecology: the Robert H. MacArthur award lecture. Ecology 73: 1943-1967

Lucrezi S, Schlacher TA (2010) Impacts of off-road vehicles (ORVs) on burrow architecture of ghost crabs (genus Ocypode) on sandy beaches. Environ Manag 45: 1352-1362

Lucrezi S, Schlacher TA, Walker SJ (2009) Monitoring human impacts on sandy shore ecosystems: a test of ghost crabs (Ocypode spp.) as biological indicators on an urban beach. Environ Monit Assess 152:413-424

McArdle BH, Anderson MJ (2001) Fitting multivariate models to community data: a comment on distance-based redundancy analysis. Ecology 82:290-297

> McClain ME, Boyer EW, Dent CL, Gergel SE and others (2003) Biogeochemical hot spots and hot moments at the interface of terrestrial and aquatic ecosystems. Ecosystems 6:301-312

McLachlan A, Jaramillo E (1995) Zonation on sandy beaches. Oceanogr Mar Biol Annu Rev 33:305-335

McLachlan A, Deruyck A, Hacking N (1996) Community structure on sandy beaches: patterns of richness and zonation in relation to tide range and latitude. Rev Chil Hist Nat 69:451-467

McLachlan A, Fisher M, Al-Habsi HN, Al-Shukairi SS, AlHabsi AM (1998) Ecology of sandy beaches in Oman. J Coast Conserv 4:181-190

Meager JJ, Schlacher TA, Green M (2011) Topographic complexity and landscape temperature patterns create a dynamic habitat structure on a rocky intertidal shore. Mar Ecol Prog Ser 428:1-12

Mislan KAS, Blanchette CA, Broitman BR, Washburn L (2011) Spatial variability of emergence, splash, surge, and submergence in wave-exposed rocky-shore ecosystems. Limnol Oceanogr 56:857-866

Moss D, McPhee DP (2006) The impacts of recreational fourwheel driving on the abundance of the ghost crab (Ocypode cordimanus) on a subtropical sandy beach in SE Queensland. Coast Manag 34:133-140

Nel R, McLachlan A, Winter D (1999) The effect of sand particle size on the burrowing ability of the beach mysid Gastrosaccus psammodytes Tattersall. Estuar Coast Shelf Sci 48:599-604

Editorial responsibility: Omar Defeo, Montevideo, Uruguay
Nel R, McLachlan A, Winter DPE (2001) The effect of grain size on the burrowing of two Donax species. J Exp Mar Biol Ecol 265:219-238

Paine R (1974) Intertidal community structure. Oecologia 15: 93-120

Peterson CH (1991) Intertidal zonation of marine invertebrates in sand and mud. Am Sci 79:236-249

- Ries L, Fletcher RJ Jr, Battin J, Sisk TD (2004) Ecological responses to habitat edges: mechanisms, models, and variability explained. Annu Rev Ecol Evol Syst 35: 491-522

> Rodil I, Lastra M, Sánchez-Mata A (2006) Community structure and intertidal zonation of the macroinfauna in intermediate sandy beaches in temperate latitudes: north coast of Spain. Estuar Coast Shelf Sci 67:267-279

Schlacher TA, Lucrezi S (2010) Experimental evidence that vehicle traffic changes burrow architecture and reduces population density of ghost crabs on sandy beaches. Vie Milieu 60:313-320

Schlacher TA, Richardson D, McLean I (2008a) Impacts of off-road vehicles (ORVs) on macrobenthic assemblages on sandy beaches. Environ Manag 41:878-892

Schlacher TA, Schoeman DS, Dugan JE, Lastra M, Jones A, Scapini F, McLachlan A (2008b) Sandy beach ecosystems: key features, sampling issues, management challenges and climate change impacts. Mar Ecol Evol Persp 29:70-90

Souza J, Gianuca N (1995) Zonation and seasonal variation of the intertidal macrofauna on a sandy beach of Paraná State, Brazil. Sci Mar 59:103-111

Stephenson T, Stephenson A (1949) The universal features of zonation between tide-marks on rocky coasts. J Ecol 37:289-305

Underwood AJ (1984) Vertical and seasonal patterns in competition for microalgae between intertidal gastropods. Oecologia 64:211-222

Underwood AJ (1997) Experiments in ecology: their logical design and interpretation using analysis of variance. Cambridge University Press, Cambridge

- Valdivia N, Scrosati RA, Molis M, Knox AS (2011) Variation in community structure across vertical intertidal stress gradients: How does it compare with horizontal variation at different scales? PLoS ONE 6:e24062

Wendt G, McLachlan A (1985) Zonation and biomass of the intertidal macrofauna along a South African beach. Cah Biol Mar 26:1-14

Zar JH (1996) Biostatistical analysis. Prentice Hall, Upper Saddle River, NJ

Submitted: December 2, 2011; Accepted: November 29, 2012 Proofs received from author(s): March 9, 2013 